\title{
REDES SOCIAIS COMO FERRAMENTAS DE TRANSPARÊNCIA EM TEMPOS DE COVID-19
}

uma análise das publicações dos boletins epidemiológicos do estado de alagoas

\author{
Paulo Ricardo Silva Lima ${ }^{1}$ \\ Universidade Federal de Alagoas/UFAL \\ pauloricardo.admpublic@gmail.com \\ Francisca Rosaline Leite Mota ${ }^{2}$ \\ Universidade Federal de Alagoas - UFAL \\ rosalinemota@gmail.com \\ Ana Paula Orico Marques Cassé ${ }^{3}$ \\ Universidade Federal de Alagoas - UFAL \\ marquespaula100@gmail.com \\ Tarlane Gomes Tenório Sales ${ }^{4}$ \\ Universidade Federal de Alagoas - UFAL \\ tarlane.tenorio@sibi.ufal.br
}

\begin{abstract}
Resumo
No período pandêmico ocasionado pelo Novo Coronavírus, surgiram muitas Fake News nas redes sociais digitais, gerando desinformação e prejudicando a Administração Pública na contenção de novos casos. Demonstra-se por meio da análise da publicização dos boletins epidemiológicos da Covid-19, disseminados nas redes sociais do Governo do Estado de Alagoas, a importância da transparência nas informações de interesse público. Essas redes, principais meios de comunicação e informação da sociedade, têm alto poder de disseminação informacional, cujo potencial "viral", proporcionado pela instantaneidade e interatividade, alcança uma infinidade de públicos. Como espaços férteis para o surgimento de Fake News e desinformação, podem gerar crises de confiabilidade e veracidade quanto às informações divulgadas pelo Governo, bem como não estimular o alagoano ao exercício da cidadania, nem agregar valor a essa sociedade. A partir do exposto, constata-se que a informação, nesse ambiente digital, deve ser tratada de forma crível, clara e responsável, com vistas a gerar maior confiabilidade, interação e acesso à informação de interesse social, bem como contribuir para a redução da circulação de Fake News e Desinformação. Adotou-se as pesquisas documental e qualitativa com uma abordagem exploratória, realizando-se a coleta de dados nas redes sociais oficiais do governo alagoano: Facebook, Instagram e Twitter.
\end{abstract}

Palavras-chave: Fake News. Desinformação. Transparência Pública. Redes Sociais Digitais.

\section{SOCIAL NETWORKS AS TOOLS OF TRANSPARENCY IN COVID-19 TIMES:}

an analysis of publications of the epidemiological newsletters in the state of alagoas Abstract

In the pandemic period caused by the New Coronavirus, many Fake News appeared on digital social networks, generating misinformation and harming the Public Administration in containing new cases. It is demonstrated through the analysis of the publication of Covid-19 epidemiological bulletins, disseminated in the social networks of the Government of the State of Alagoas, the importance of transparency in information of public interest. These networks, society's main means of communication and information, have a high power of information dissemination, whose "viral" potential, provided by instantaneity and interactivity, reaches an infinite number of

\footnotetext{
${ }^{1}$ Mestrando em Ciência da Informação pela Universidade Federal de Alagoas- UFAL. Bacharel em Administração Pública pela Universidade Estadual de Alagoas - UNEAL.

${ }^{2}$ Doutora e Mestre em Ciência da Informação pelo PPGCI/UFMG. Docente do Programa de Pós-Graduação em Ciência da Informação - PPGCI/UFAL.

${ }^{3}$ Mestranda em Ciência da Informação - PPGCI/UFAL.

${ }^{4}$ Mestranda em Ciência da Informação - PPGCI/UFAL.
}

cc) (ㅇ) Esta obra está licenciada sob uma licença BY NC SA Creative Commons Attribution 4.0 International (CC BY-NC-SA 4.0). 
audiences. As fertile spaces for the emergence of Fake News and disinformation, they can generate crises of reliability and veracity regarding the information released by the Government, as well as not stimulating Alagoas to exercise citizenship, nor add value to this society. From the above, it appears that information, in this digital environment, must be treated in a credible, clear and responsible manner, with a view to generating greater reliability, interaction and access to information of social interest, as well as contributing to the reduction of circulation of Fake News and Disinformation. Documentary and qualitative research was adopted with an exploratory approach, with data being collected on the official social networks of the Alagoas government: Facebook, Instagram and Twitter.

Keywords: Fake News. Disinformation. Public Transparency. Digital Social Networks.

\section{INTRODUÇÃo}

A informação faz parte da rotina da sociedade moderna, estando disseminada nos mais diversos modelos e bases informacionais como plataformas eletrônicas, mídias sociais, redes sociais digitais, entre outras. Entretanto, essa dinamicidade do conteúdo informativo e as formas de consumo pela população fazem emergir uma série de questionamentos quanto à confiabilidade e à veracidade das informações disponíveis nesses ambientes, sobretudo nas redes sociais digitais.

No período pandêmico ocasionado pela crise respiratória, oriunda do novo coronavírus, definido cientificamente pela Organização Mundial de Saúde (OMS) como Sars-Cov-2 ou Covid-19, muitas Fake News referentes às formas de contágio, ao número de pessoas infectadas, de óbitos e de uma possível cura para essa doença viral estão sendo veiculadas nas redes sociais digitais, gerando desinformação social em massa, prejudicando a ação da administração pública no que tange às políticas de contenção de novos casos.

Diante dessa realidade, as entidades públicas de saúde, em sintonia com outros órgãos públicos brasileiros, têm se preocupado em disponibilizar informações verídicas para a população por meio de suas mídias digitais. Faz-se oportuno destacar que essa atitude de promover a publicidade das informações sobre a Covid-19, as tornam transparentes e consonantes com o princípio da publicidade e do direito fundamental à informação que todo cidadão possui, estabelecidos na Carta Magna (BRASIL, 1988).

Em Alagoas, o governo estadual tem sido o principal responsável pela publicidade e transparência dos casos relacionados à Covid-19. A divulgação dos dados tem sido organizada em boletins epidemiológicos e estes publicados nas redes sociais oficiais do governo a partir do dia 27 de março de 2020, quando os primeiros casos começaram a ser confirmados.

Destarte, a referente pesquisa teve por objetivo analisar a periodicidade da publicação dos boletins epidemiológicos da Covid-19 divulgados nas redes sociais do Governo do Estado de Alagoas, bem como demonstrar a importância da transparência, no que se refere aos casos 
relacionados à doença. Como processo metodológico, realizou-se uma pesquisa exploratória nas redes sociais Instagram, Twitter e Facebook, tendo como base teórica a pesquisa documental, num recorte de tempo de 27 de março a 05 de julho de 2020.

No último semestre de 2019 um novo vírus da família corona, catalogado como Sars Cov2 provoca a doença denominada Covid-19, cujos efeitos no organismo humano são desde sintomas leves aos agudos, como tosse, febre, cansaço, dores musculares, inflamação da garganta, dos pulmões e crises respiratórias, podendo levar à morte. (TANIGUCHI, 2020). O vírus fica alojado nas vias respiratórias do agente, que quando tosse ou espirra, expele-o em pequenas gotículas, podendo infectar outras pessoas. Além dessa transmissão direta, o vírus também pode ficar ativo por horas ou dias em superfícies de madeira, vidro, plástico e outros materiais, o que facilita a contaminação (TEIXEIRA, 2020).

Devido a essa facilidade de contágio, em 2020 muitos países foram atingidos pelo coronavírus, e devido aos seus efeitos letais a OMS decretou o alerta de pandemia. Até o dia 10 de julho de 2020 o número de infectados era de 12.102.328, e o de óbitos era de 551.046 em 216 países, conforme dados da OMS (2020). Para que o número de infectados não aumentasse, países como os Estados Unidos da América, Portugal e Japão adotaram um isolamento social em massa, mantendo a população em quarentena. Essa estratégia também foi adotada pelo Brasil, quando os primeiros casos começaram a surgir.

O primeiro caso testado positivo para Covid-19 no Brasil, ocorreu em fevereiro de 2020, entretanto, não é possível dizer, de forma precisa, se o vírus já estava no país antes da mencionada data, pois muitas pessoas vieram de outros países com os sintomas e, ainda, não haviam sido submetidas aos testes (LEMOS, 2020). Nesse contexto, além da crise do coronavírus, observa-se que outros problemas de cunho político e social, como as trocas de ministros da Pasta da Saúde, a ausência de consenso entre os estados e o Governo Federal quanto às medidas de enfrentamento, às Fake News relacionadas à Covid-19, e a ausência de informação também contribuíram para o agravamento da doença e para a insatisfação social em relação às ações das entidades públicas.

Sendo a informação um dos principais elementos para a efetividade da transparência na sociedade moderna e objeto de discussão no campo jurídico, foi necessária a criação de normas de utilização e acesso à informação, contempladas nos diversos dispositivos legais nacionais e internacionais (RODRIGUES, 2014). É importante ressaltar que o direito ao acesso à informação se trata de um direito elencado como fundamental do cidadão de informar e ser informado sobre assuntos de seu interesse, devendo a administração desenvolver meios de efetivá-lo (CANOTILHO, 1992). No mesmo sentido, para Guerra e Carvalho (2019, p. 4) “O 
acesso à informação, além de ser um direito do cidadão, tem um papel determinante para o exercício da cidadania através do controle social da Administração Pública, impondo dessa maneira limites aos gestores públicos $[\ldots] ”$.

De acordo com Rosa e Urbanetto (2014, p. 142) “o cidadão bem informado tem melhores opções e condições de conhecer e exigir outros direitos essenciais, como saúde, educação e benefícios sociais. Por estes motivos, o acesso à informação pública vem sendo, cada vez mais, reconhecido como um direito em várias partes do mundo". Quando o direito de acesso à informação é colocado em prática, as pessoas tendem a enxergar as mazelas que acometem o bom funcionamento do serviço público e concomitantemente a isso, possibilita que o cidadão consiga apontar as deficiências e possa a responsabilizar os culpados.

Nesta senda, Rodrigues (2014, p. 04) esclarece que:

\begin{abstract}
O acesso à informação dá aos cidadãos controle democrático sobre o trabalho das autoridades, facilitando a descoberta de diferentes formas de irregularidades, atos ilegais e corrupção. Ao mesmo tempo, confere aos cidadãos os recursos políticos suficientes para lhes permitir participar de maneira plena, como cidadãos iguais (com igual acesso aos dados e informes públicos), da tomada de decisões coletivas às quais estão obrigados.
\end{abstract}

A disseminação das informações relativas aos atos realizados no âmbito da administração pública brasileira decorre do princípio constitucional da publicidade, uma vez que a sociedade enquanto interessada e financiadora da máquina pública tem o direito de saber como estão sendo utilizados os recursos públicos e quais ações são realizadas em prol do coletivo. De forma subsidiária a este entendimento, o art. 5º inciso XXXIII da Constituição esclarece que "todos têm o direito a receber dos órgãos públicos informações de seu interesse particular, ou de interesse coletivo ou geral, que serão prestadas no prazo da lei, sob pena de responsabilidade [...]" (BRASIL, 1988).

Essa publicização, além de reduzir as incertezas e a disseminação de informações falsas, também colabora para a construção de uma administração pública transparente, o que fortalece o Estado democrático e a satisfação social (RODRIGUES, 2014). É necessário pontuar que foram instituídos alguns dispositivos legais para formalizar a transparência na administração pública, sendo o principal deles a Lei de Acesso à Informação (LAI), sob o n. 12.527/2014. De acordo com a supracitada lei, os entes da administração direta e indireta devem construir meios de comunicação que proporcionem a todo cidadão informações relativas a questões pessoais ou coletivas, devendo o órgão ou a entidade pública proporcioná-las com o fito de satisfazer a necessidade informacional (BRASIL, 2014). 


\section{O CIBERESPAÇO E O SURGIMENTO DAS REDES SOCIAIS}

A internet, ambiente virtual conectado em rede, caracterizada como um sistema de comunicação que interliga dados por meio de computadores e outros dispositivos, cria conexões que privilegiam a troca de informação, abrindo, assim, um vasto campo de possibilidades para os atores conectados.

Também conhecida como Ciberespaço, a internet, tem fomentado a produção e o compartilhamento de dados e informações, facilitando a interatividade e promovendo a instantaneidade no ato de coletá-los e recuperá-los por meio de uma série de tecnologias digitais. Além de interligar atores de diversas culturas e países, tem um alto poder de disseminação, permitindo, dessa forma, um maior alcance no número de pessoas e ultrapassando as barreiras temporais e geográficas a um baixo custo.

Conforme o entendimento de Santos (2017, p. 30), esse espaço virtual seria o da produção cultural e fenômenos sociotécnicos que emergiram da relação entre seres humanos e objetos técnicos digitalizados em conexão com a internet, rede mundial de computadores, caracterizam e dão forma à cultura contemporânea como cibercultura

As redes sociais eletrônicas, virtuais, digitais ou onlines, são espaços nos quais diversos atores por meio de conexões se relacionam e se informam sobre os mais diversos assuntos locais e mundiais, compartilham experiências e propõem soluções para infinitos problemas do cotidiano (LÉVY, 1999; CASTELLS, 1999; REBS; ZAGO, 2011).

Na mesma linha de raciocínio, Araújo (2014, p.2) entende que:

As redes sociais, compreendidas como um conjunto de atores conectados por nós de relações de amizades, trabalho ou troca de informação, ampliaram imensamente as possibilidades de interconexão entre os sujeitos sociais na web e trouxe inúmeras complexidades à participação social [...].

Essas redes tornaram-se populares a partir dos anos 2000, quando o Ciberespaço se tornou mais democrático e utilizado por grande parte da sociedade por meio de computadores, notebooks, tablets e smartphones, ainda sim, são consideradas os principais meios de comunicação e informação da sociedade hodierna, enquanto os outros meios infocomunicacionais tornaram-se obsoletos ou pouco utilizados, como os jornais e revistas impressos, as rádios e os telefones fixos.

Segundo as pesquisas de We Are Social e Hootsuite (KEMP, 2020), realizadas no período de abril de 2019 e janeiro de 2020, verificou-se que, hoje, no mundo há 7,75 bilhões de seres humanos, dos quais 4,54 bilhões são usuários da internet e 3,8 bilhões das redes sociais 
digitais, o que representa, respectivamente, $59 \%$ e $49 \%$ da população mundial.

Em relação ao Brasil, os dados apurados apontam para a existência de 211,8 milhões de pessoas, das quais 150,4 milhões são usuárias da internet e 140,0 milhões das redes sociais digitais, o que representa, respectivamente, os percentuais de $71 \%$ e $66 \%$ da população brasileira. Entre abril de 2019 e janeiro de 2020, a população brasileira aumentou 0,7\% (1,5 milhões), além disso, houve indicadores de crescimento digital em 6,0\% (8,5 milhões) no número de usuários da internet, bem como em 8,2\% (11 milhões) no número de usuários ativos nas referidas redes sociais (KEMP, 2020).

Destaca-se, em especial, o aumento de adeptos às Redes Sociais e o e potencial de alcance a uma parcela, cada vez maior, de públicos diversos (KEMP, 2020). Além disso, verifica-se, também, as plataformas de mídia social mais utilizadas, no Brasil, por pessoas na faixa etária dos 16 aos 64 anos, conforme ilustrado no Gráfico 1.

Gráfico 1 - as redes sociais mais acessadas no Brasil conforme os relatórios da We Are Social e Hootsuite (KEMP, 2020)

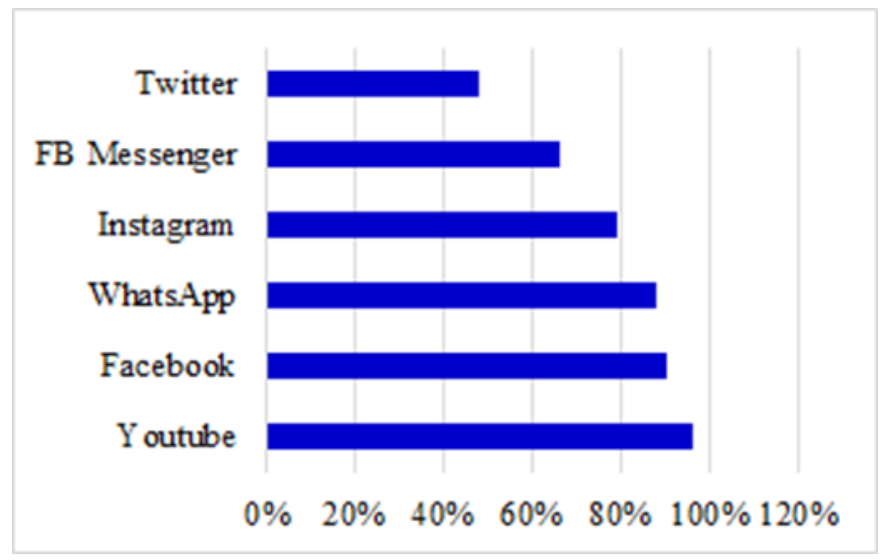

Fonte: Adaptado pelos autores (2020)

Dessa forma, compreende-se o porquê de as redes sociais da internet serem evidenciadas como importantes meios de comunicação e fluidas na troca de informação, pois abarcam qualidades como conectividade, instantaneidade e praticidade na interação entre os seus atores. Empresas Privadas e Instituições Públicas se apercebem das várias possibilidades de uso dessas plataformas como poderosas ferramentas de aproximação com seus públicos-alvo e com a sociedade em geral. Há um esforço para estar presente em uma gama de redes sociais, porém, apenas essa presença digital não estabelece uma interação e comunicação eficazes, se faz necessário a adoção de estratégias que atraiam tais usuários (RODRIGUEZ, 2016).

Essas redes têm um alcance impulsionado pelas interações que nelas acontecem, por 
conseguinte, verifica-se um alto crescimento em suas audiências, embasado pelas multiconexões que ocorrem em virtude da convergência a um ponto em comum, proporcionando o alcance exponencial de públicos, dos indivíduos em si aos seus amigos, aos amigos dos seus amigos, a outros desconhecidos, e assim por diante, num crescimento em camadas (MARQUES; DELBART, 2015).

De acordo com Da Silva, Ribeiro e Silva Filho (2018), as redes sociais digitais tornaramse, então, um ambiente propício para o estreitamento das relações entre a Administração Pública e o cidadão. Por meio de uma comunicação mais dinâmica, o Estado aumenta a sua capacidade para estimular o cidadão à consciência cidadã, tornando-o mais crítico e fiscalizador para que, com base nesse feedback, possa melhorar a qualidade dos serviços prestados à comunidade.

A comunicação pública é significativamente ampliada por esse cenário cibernético e tem a capacidade de cumprir a função de orientar a coletividade de forma crível e transparente quanto ao uso e às ações do poder administrativo, promovendo o compartilhamento de informações e políticas públicas que fortaleçam a cidadania, refletindo na reputação digital da Administração, bem como, abrindo espaço para a colaboração e participação social.

\section{FAKE NEWS: CONCEITO E DISCUSSÕES}

As Fake News, conhecidas como notícias falsas, são divulgadas e compartilhadas como se fossem verdadeiras, principalmente nas mídias digitais, e também veiculadas com o intuito de atingir interesses de indivíduos ou grupos. (RECUERO; GRUZD, 2019). A transmissão de informações por esses meios digitais pode ser influenciada por diversas finalidades, bem como interesses de ordem política, econômica e social, gerando dificuldades na distinção do que é verdadeiro e do que é falso.

Segundo a Unesco (2019, p. 4) existem dificuldades para se encontrar um significado direto e compreensível do termo Fake News, pois, as notícias "[...] se tornam informações verificáveis de interesse público, e as informações que não atendem a esses padrões não merecem o rótulo de notícias". A necessidade de divulgar e compartilhar informações nas redes sociais digitais pode facilitar o uso de narrativas compostas por falsidades parciais ou totais.

No contexto científico, nota-se um movimento retrógrado de deslegitimação e descrença da Ciência por meio das Fake Sciences. Nesse raciocínio, Oliveira, Martins e Toth (2020, p. 93 ) as compreendem “[...] como uma apropriação dos discursos científicos para a propagação de uma informação que vá contra as pesquisas científicas, implicando uma série de disputas em prol do controle e da verificação da informação". Dessa maneira, observa-se que às Fake News 
e às Fake Sciences têm um poder de disseminação massiva, o que concorre para uma desinformação social, promotora de conflitos de interesses no escopo científico.

No âmbito das Fake News, repara-se que não são discutidas somente no contexto contemporâneo, pois segundo o entendimento de Jardim e Zaidan (2018, p. 3), seriam “[...] algo que sempre existiu, apenas adaptaram-se a um novo contexto, formato e mídia.” Ou seja, já circulavam nas mídias, fazendo parte do constructo político e histórico da sociedade, como, por exemplo, as notícias da revolta da vacina, no século XX, e os casos de microcefalia em bebês, causados pelo surto do Zika Vírus no Brasil no ano de 2017, alcançando a população, de forma célere, deturpada e negativa (SOUSA, 2017).

Notícias falsas podem provocar diversas reações no consumidor final, pois “[...] fazem apelo às emoções e às crenças coletivas e individuais" (SOUSA, 2017, p. 5). Elas têm a função de ludibriar o psicológico humano, ao mesmo tempo que podem modificar o seu comportamento em relação a determinada pessoa ou situação. Observa-se que há um fortalecimento desse fenômeno, somado a essas crenças e aos apelos pessoais, principalmente em sua propagação pelas redes sociais da internet (MELO, et al., 2020).

Nesse contexto, para Bauman (2001, p. 30), a sociedade, também chamada de sociedade da modernidade fluida, não “ [...] mais reconhece qualquer alternativa para si mesma e, portanto, sente-se absolvida do dever de examinar, demonstrar, justificar (e que dirá provar) a validade de suas suposições tácitas e declaradas”. Esse raciocínio traz uma visão de um descompromisso dos indivíduos em questionar as informações que estão dispostas ao seu redor, assumindo uma postura ausente de crítica, pois [...] os conteúdos informacionais têm sido disseminados pela sociedade contemporânea, muitas vezes, de maneira unilateral, sendo consumidos sem muito questionamento crítico, de forma aleatória” (BAUMAN, 2001, p. 32). A aceitação de informações sem a verificação de sua veracidade, juntamente com a facilidade de transmissão pelos meios de comunicação eletrônicos, demonstram a vulnerabilidade dos indivíduos quanto à característica de persuasão das Fake News no ciberespaço.

Demonstra-se que o propósito das Fake News se relaciona com o controle da divulgação das informações, o que pode trazer como consequência a desinformação. A desinformação não se trata de um termo novo oriundo da evolução tecnológica, pois além de ser utilizada como estratégia bélica em períodos de guerra no passado para combater os excessos de espionagem, esta já estava presente em diversos meios de informação, como livros, jornais, discursos, entre outras fontes informativas (BRISOLA; BEZERRA, 2018). No mesmo sentido, Moura et al. (2019, p. 3) esclarecem que a desinformação é “[...] uma informação falsa, enganosa e/ou imprecisa, que pode ser criada propositalmente com prejuízo a alguém ou erroneamente". 
Assim, torna-se comum a adulteração de informações que são disseminadas de forma ágil e massiva por meio da utilização de recursos tecnológicos. Por esse motivo, entende-se a necessidade de se buscar uma definição acerca das terminologias que perpassam os meios comunicativos entre mídia e sociedade.

Apesar da semelhança entre as terminologias Fake News e desinformação, nota-se que a primeira tem a intenção de propagar falsas notícias, ou seja, disseminá-las de forma mentirosa. Já a desinformação não seria uma notícia necessariamente falsa, isso por que, muitas vezes pode-se ocorrer a divulgação de informações deturpadas ou mal organizadas, em virtude, por exemplo, da ausência ou da falta de transparência dessa informação. A liberdade dos indivíduos para manifestar opiniões e compartilhar um ponto de vista que considerem conveniente é o que vai definir como a desinformação será disseminada, e por isso pode haver semelhanças em suas conceituações (MOURA et al., 2019).

A compreensão das informações tem sido dificultada cada vez mais pelas próprias características das redes sociais, que valorizam a instantaneidade na forma como são disseminadas. Salienta-se ainda, que as notícias emergentes têm sido o principal alvo do fenômeno Fake News, bem como da desinformação. No que tange às informações acerca da pandemia do novo coronavírus, observa-se que inúmeras divulgações de notícias sobre a temática foram encontradas com a descrição errônea de fatos, falhas de interpretação e contradições, o que pode causar confusão da população acerca do entendimento do que é divulgado, o que a torna vulnerável (HUIDU, 2020).

Como forma de combater as consequências causadas pela frenética necessidade de se buscar e compartilhar informações, sem a devida verificação da veracidade, o Governo do Estado de Alagoas sancionou uma lei que pune a propagação de Fake News sobre epidemias, endemias, pandemias e conteúdos relacionados à Covid-19. Essa lei, de n ${ }^{\circ} 8.266$, publicada no dia 10 de junho de 2020, prevê o pagamento de multas para aqueles que divulgarem por qualquer meio, uma notícia ou informação falsa com a intenção de prejudicar de forma integral ou parcial. Com essa sanção, o estabelecimento de penalidades é uma forma de minimizar a veiculação de informação falsa e desinformação, que altere, corrompa ou distorça a verdade sobre essas situações de emergência sanitária no Estado de Alagoas (ALAGOAS, 2020).

\section{MATERIAIS E MÉTODOS}

O percurso metodológico adotou a pesquisa qualitativa com uma abordagem exploratória. A pesquisa exploratória busca uma aproximação do pesquisador ao objeto a ser 
estudado para que assim seja possível levantar hipóteses e respostas (GIL, 2008). Nesse sentido, foram exploradas as postagens divulgadas nas redes sociais eletrônicas do Governo de Alagoas, bem como as suas diversas características com o objetivo de facilitar a compreensão das informações.

Quanto à coleta de dados, esta foi realizada por meio de uma pesquisa documental que, de acordo com Lakatos e Marconi (2019), trata-se de uma fase em que o pesquisador recolhe as informações sobre seu objeto de estudo, podendo estas serem escritas ou não. Para este trabalho, foram consultados estudos nacionais e internacionais acerca das temáticas: redes sociais digitais, Fake News, direito à informação e transparência no âmbito da administração pública brasileira.

Destarte, as coletas de dados desta pesquisa foram efetuadas nas três principais redes sociais utilizadas pelo governo alagoano, a saber: Facebook, Instagram e Twitter. De acordo com o relatório da pesquisa We Are Social (2019) e com o portal Statista (2019) essas redes estão entre as mais utilizadas pelas populações mundial e brasileira. Por meio delas foi possível identificar e comparar a partir de um gráfico e um quadro os números de seguidores, curtidas, comentários, e compartilhamentos das postagens referentes aos boletins.

No que se refere aos boletins epidemiológicos, foi possível verificar o avanço do coronavírus no Estado de Alagoas, bem como o número de casos confirmados, suspeitos, recuperados e de óbitos, ocorridos no período de 06 de abril a 05 de julho de 2020. Faz-se necessário pontuar ainda que esta pesquisa não tem qualquer interesse em discutir questões políticas, uma vez que o objetivo principal se fundamenta nas análises da periodicidade da divulgação dos boletins epidemiológicos da Covid-19 nas redes sociais digitais oficiais do Governo de Alagoas, na observação do movimento interativo ocorrido por conta dessa divulgação, e também na demonstração da importância da transparência, frente ao aumento do fluxo informacional ocorrido por conta do avanço do vírus e da necessidade dos usuários terem acesso a informações confiáveis, disponíveis nos perfis oficiais.

\section{ANÁliSE dOS RESUltados SOBRE AS PUBLICAÇÕES DOS BOLETINS EPIDEMIOLÓGICOS NAS REDES SOCIAIS DO GOVERNO DO ESTADO DE ALAGOAS}

Conforme as informações disponíveis, no dia 10 de julho de 2020, nos perfis oficiais das redes sociais do Governo do Estado de Alagoas, data final da coleta de dados para os fins desta pesquisa, constatou-se que o perfil oficial do Facebook foi criado em 13 de novembro de 
2018, tendo como missão informar aos seguidores sobre as principais ações do Governo (FACEBOOK, 2020). Seu número atual de seguidores ultrapassa os 110 mil, além disso, também dispõe de um grupo privado, chamado de Coletiva On-Line, composto de 193 membros cujo objetivo é informar e discutir assuntos de interesse dos cidadãos alagoanos, em tempo real. Ressalta-se, ainda, que nessa plataforma não há o espaço Stories, em que os conteúdos podem ser visualizados num período limitado de 24 horas.

Verificou-se, também, que o perfil oficial do Instagram, @ governodealagoas, foi criado em 06 de fevereiro de 2014 sob o slogan "Governo de \#Alagoas, lugar de todos os alagoanos", e possui um selo de verificação que comprova sua autenticidade (INSTAGRAM, 2020). Até a data final dessa coleta, o perfil seguia 1.178 outros perfis, contabilizava 144 mil seguidores e havia disponibilizado em seu Feed 4.610 publicações. No espaço reservado aos Destaques (highlights), observou-se que os conteúdos são organizados por assunto: Decreto Covid-19; FatoXFake; Covid-19; Por Nide Lins; Se Liga; Obras; Fazer+; Concursos e Pinheiro. Constatou-se, ainda, que, no destaque Covid-19, os conteúdos têm vieses educativos e informativos acerca da doença. Quanto aos espaços reservados ao Feed, Stories e IGTV, notouse que dispõem de conteúdos informacionais, como: divulgações de ações, obras e campanhas do Governo, e também depoimentos, orientações gerais e de cunho educativo à população.

Já o perfil no Twitter, @GovernoAlagoas, foi criado em julho de 2009 e contabilizou o total de 23.500 seguidores até a referida data final da coleta. Nele são publicados eventos, palestras e as diversas ações do governo em prol da sociedade. Neste período de Covid-19, muitas informações referentes às Fake News, atitudes preventivas, decretos de isolamento e boletins epidemiológicos estão sendo publicados constantemente para manter a população informada e reduzir as incertezas.

\subsection{SOBRE O BOLETIM EPIDEMIOLÓGICO}

Devido ao aumento de casos relacionados à Covid-19, a Secretaria de Estado de Saúde de Alagoas (SESAU), juntamente com a Superintendência de Vigilância em Saúde (SUVISA), seguindo o modelo de organização de dados sobre a doença em outros estados, passou a organizar os números de casos confirmados, suspeitos, recuperados e de óbitos em Alagoas, no formato de boletins diários. Esses boletins passaram a ser publicados nas redes sociais do governo de Alagoas (Facebook, Instagram e Twitter), como forma de manter a população informada sobre o avanço da doença.

O primeiro boletim foi publicado no mural principal (feed) das redes sociais a partir do 
mês de abril, sendo no Facebook e Twitter dia 08 de abril de 2020 e no Instagram dia 06 de abril de 2020. Oportuno se faz destacar que foi divulgado nos Stories do Instagram, datado de 27 de março de 2020, um boletim, que informava a quantidade de casos relacionados à Covid19, sendo 12 confirmados, 302 suspeitos, 225 descartados e um 01 caso de cura.

Verificou-se ainda que os boletins começaram a ser publicados de forma contínua, a partir do mês de abril, a exceção de alguns dias. No Facebook não houve publicação de boletins nos dias 09, 11, 12, 13 e 22 de abril, nos dias 07, 17 e 25 de maio, e em 23 de junho; no Instagram a publicação não ocorreu nos dias 07 e 11 de abril e 29 de maio; já no Twitter, não foram publicados os boletins dos dias 09, 10, 11, 12, 13 e 30 de abril e nos dias 02 e 29 de maio.

Quanto à postagem dos boletins epidemiológicos, realizada no período dessa pesquisa, observou-se a periodicidade de sua divulgação nos perfis do Governo de Alagoas nas redes Facebook, Instagram e Twitter, coletando-se o total de suas publicações.

Quadro 1 - Publicações dos boletins epidemiológicos nas redes sociais do Governo de Alagoas

\begin{tabular}{|l|r|}
\hline \multicolumn{1}{|c|}{ Rede Social } & Total de Publicações \\
\hline Instagram & 91 \\
\hline Twitter & 82 \\
\hline Facebook & 80 \\
\hline Total de Publicações & $\mathbf{2 5 3}$ \\
\hline
\end{tabular}

Fonte: elaborado pelos autores (2020)

Durante os 91 (noventa e um) dias decorridos no período de 06 de abril a 05 de julho de 2020, constatou-se que na rede social Instagram houve uma maior frequência do número de postagens diárias dos boletins em relação àquelas observadas nas outras mídias, alcançando o patamar de 35,97\%. Com relação ao Facebook e o Twitter aferiram-se 31,62\% e 32,41\%, respectivamente.

\subsection{SOBRE AS INTERAÇÕES NAS REDES SOCIAIS}

Para essa pesquisa, foi observada a quantidade de interações movimentada nos perfis oficiais das redes sociais do Governo do Estado de Alagoas: Instagram, Facebook e Twitter. Para isso, foi efetuada a coleta do número de interações dos seguidores em relação aos boletins 
publicados, considerando, em separado, as curtidas, os comentários e os compartilhamentos, no período de 06 de abril a 05 de julho de 2020.

Gráfico 2 - Interações das Redes Sociais Instagram, Facebook e Twitter do Governo do Estado

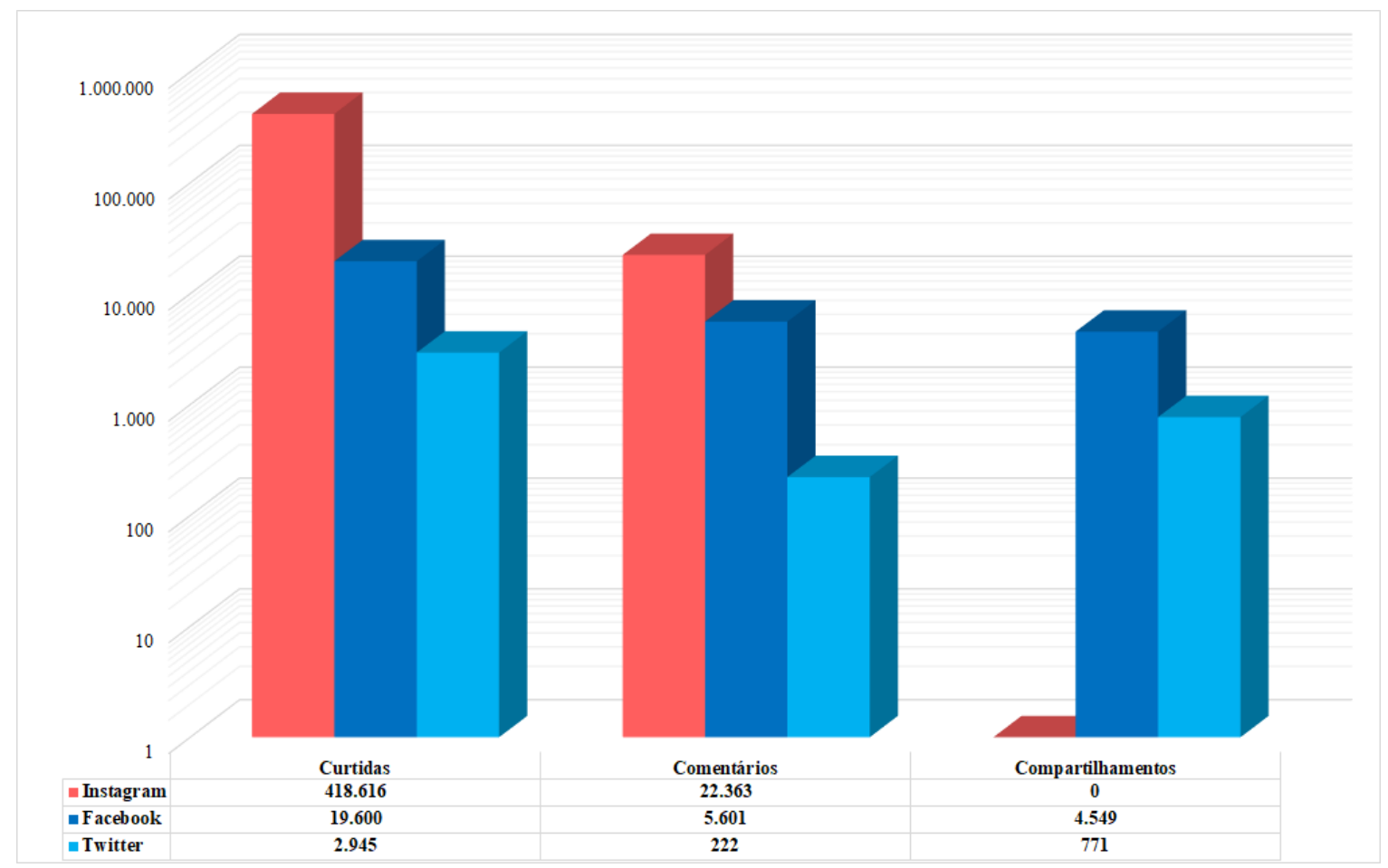

Fonte: elaborado pelos autores (2020).

Contabilizando-se o total de interações das três plataformas, chegou-se ao resultado de 441.161 curtidas, 28.186 comentários e 5.320 compartilhamentos, o que demonstra que esse perfil movimenta um número razoável de pessoas que interagem nas redes, principalmente por meio de curtidas. Salienta-se ainda que o Instagram não permite a visualização do número de compartilhamentos de outro perfil.

Quanto à quantidade de curtidas dos boletins epidemiológicos, no período analisado, o Instagram obteve um total de 94,90\%, atingindo, em 01 de maio, o maior número (10.014 mil) e o menor (2.211 mil) no dia 30 de junho; já o Facebook totalizou 4,44\%, alcançando, no dia 23 de abril, o maior número (451) e o menor número (82), no dia 30 de junho e, no que se refere ao Twitter, este totalizou 0,66\%, auferindo o maior número (102) em 29 de abril e o menor (4) no dia 21 de abril.

Acerca dos comentários postados nas três redes analisadas, foi possível perceber algumas diferenças em relação aos quantitativos.

O Instagram obteve 22.363 comentários, o que representa um total de 79,34\% dessa 
interação. O boletim com maior índice de comentários foi o publicado no dia 18 de abril contabilizando 1.142. Em 26 de junho, foram publicados 33 comentários, sendo considerado o boletim com menor quantidade.

No Facebook, o total de comentários foi de 5.601, o que representa 19,87\% do total de interação. O boletim com maior registro, atingiu 225 comentários no dia 18 de abril. Já nos dias 30 de junho e 02 de julho, ambos, tiveram o menor índice com 10 comentários.

Em relação ao Twitter, houve 222 comentários, totalizando $0,79 \%$. O maior número de comentários foi observado nos boletins dos dias 03 de maio e 02 de junho, possuindo, ambos, 10 comentários cada. Entretanto, existiram alguns boletins que não obtiveram comentário algum, especificamente nos dias 16, 21 e 25 de abril, 04, 05, 12, 22 e 25 de maio, nos dias 01, 10, 15, 17, 18, 19, 20, 24, 26, 27 de junho, e nos dias 01, 02, 03 e 04 de julho.

Dentre alguns comentários, observaram-se solicitações de seguidores para que o governo publicasse o número de casos descritos por bairros e cidades; outros solicitaram um posicionamento mais eficaz no tocante à redução de casos, como também elogiavam o governo e os profissionais que estão atuando na linha de frente no combate à Covid-19.

Com relação aos compartilhamentos visualizados nas redes Facebook e Twitter, verificou-se diferenças entre os quantitativos.

O Facebook contabilizou 4.549 compartilhamentos, atingindo 85,51\%. No dia 18 de abril foram registradas 171 interações, sendo o maior número alcançado. A menor quantidade foi de 13 compartilhamentos, ocorridos no dia 30 de junho.

No Twitter, houve um total de 771 compartilhamentos de tweets (retweets), o que corresponde a 14,49\%. No dia 29 de abril, o boletim foi compartilhado 37 vezes, sendo o maior número de retweets. O menor número foi de, apenas, um retweet, o que ocorreu nos dias $09 \mathrm{e}$ 19 de junho.

\section{CONSIDERAÇÕES FINAIS}

Os governos têm o dever de observar o princípio constitucional da publicidade e, também, os requisitos dispostos na LAI, que buscam uniformizar o acesso e facilitar a gestão da informação. Essa lei, ainda obriga que os órgãos e entidades da Administração Pública realizem uma gestão transparente da informação, permitindo o seu amplo acesso, bem como efetuem a divulgação de dados públicos, garantindo-lhes a integridade e a constante disponibilidade.

No que diz respeito ao período pandêmico e a realidade alagoana, a divulgação desses 
boletins, além de proporcionar transparência da administração pública sobre a pandemia sanitária da Covid-19, dá aos cidadãos o acesso à informação de interesse social, também contribui para a redução da circulação de Fake News acerca da doença nos ambientes virtuais, que acaba causando diversos danos de cunho psicológico e comportamental.

As redes sociais Facebook, Instagram e Twitter do Governo de Alagoas utilizadas para divulgar os boletins epidemiológicos da Covid-19 tiveram um elevado alcance de interações dos usuários, seja curtindo, compartilhando ou comentando, sendo os perfis do Facebook e o Instagram os que mais tiveram participação social, o que justifica por serem as mais preferidas pela população brasileira. Observou-se que os primeiros boletins publicados possuíam mais interações quando comparados aos últimos analisados, infere-se, então, que há certo desinteresse dos seguidores em conhecer e acompanhar tais informações ou ainda um sentimento de comodidade e aceitação da situação como algo comum.

Apesar da elevada interação dos usuários, não houve uma maior participação do Governo de Alagoas no que tange à resposta das perguntas feitas nas postagens dos boletins, o que demonstra uma falta de retorno da equipe que as gerencia. Um dos principais problemas apontados pelos usuários quanto aos boletins, reside na desconfiança da veracidade deles, pois, alguns alegavam que os números não condiziam com a realidade e que pessoas que haviam morrido por problemas diversos, estavam sendo computadas como se fossem vítimas da Covid19.

Embora tenham sido publicados Decretos de isolamento pelo governo alagoano, alguns números continuam a subir. De acordo com a análise do boletim do dia 05 de julho de 2020, o total de casos confirmados atingiu o número de 39.935, já o de recuperados 31.245, observandose, dessa maneira a representação de 78,3\% dos casos de pessoas recuperadas em relação ao número de casos confirmados. Constatou-se, ainda, na referida data, que foi atingida a marca de 1.153 óbitos, o que representa $2,88 \%$ do universo de casos confirmados.

Destarte, não basta apenas isolar a sociedade, é preciso entender as suas necessidades e buscar saná-las para que haja uma quarentena eficiente e, assim, seja possível reduzir o número de casos, outrossim, seria necessário, também, a realização de uma comunicação em rede com o fito de se definir um planejamento estratégico funcional para equacionar e gerenciar melhor a divulgação da informação. Diante dessa situação, se faz necessário que as entidades públicas desenvolvam meios para dar transparência às informações referentes à realidade em que os municípios, estados e o país se encontram frente ao novo coronavírus, bem como, às medidas que estão sendo tomadas para a contenção da Covid-19.

Neste sentido, as redes sociais demonstram ser ferramentas estratégicas e eficientes 
quanto à disseminação de informações em tempo real, todavia, se faz necessário planejar o gerenciamento dessas plataformas digitais, tratando os capitais, o usuário e a informação, de forma criteriosa. Buscar informar o usuário de forma crível e clara, oferecendo conteúdos que agreguem valor e facilitem a relação com o seu público-alvo.

No que se refere aos perfis digitais da Administração Pública, essa necessidade tem um peso maior, em virtude da responsabilidade quanto à promoção da transparência, com vistas a estimular a sociedade ao exercício da cidadania. Dessa forma, o investimento em um gerenciamento de uma comunicação eficaz das redes sociais, explorando todas as suas ferramentas e funcionalidades em prol do atendimento das demandas informacionais de seus usuários, poderá gerar maior confiabilidade, interação e fidelização, não deixando espaço para a disseminação das Fake News, nem para a criação de desinformação nesse ambiente digital. 


\section{REFERÊNCIAS}

ALAGOAS, Secretaria do Estado de. Diário Oficial do Estado de Alagoas. Disponível em: http://www.imprensaoficialal.com.br/wp-content/uploads/2020/06/DOEAL-10_06_2020COMPLETO.pdf. Acesso em: 14 jun. 2020.

ALAGOAS. Secretaria de Estado da Saúde confirma mais 3 casos de Covid-19, 2020. Disponível em:http://www.saude.al.gov.br/2020/03/19/secretaria-de-estado-da-saudeconfirma-mais-tres-casos-de-covid-19/. Acesso em: 14 jun. 2020.

ARAÚJO, R. F. Atores e ações de informação em redes sociais na internet: pensando os regimes de informação em ambientes digitais. DataGramaZero, v. 15, n. 3, 2014. Disponível em: https://brapci.inf.br/index.php/res/v/8239. Acesso em: 04 jun. 2020.

BAUMAN, Z. Modernidade líquida. Tradução Plínio Dentzien. Rio de Janeiro: Jorge Zahar, 2001.

BRASIL, E. N. DE A. P. Pierre Zémor fala sobre comunicação pública na ENAP. Revista do Serviço Público, v. 60, n. 2, p. p. 197-200, 23 jan. 2014.

BRASIL. Constituição da república federativa do brasil de 1988. Disponível em:http://www.planalto.gov.br/ccivil_03/constituicao/constituicao.htm. Acesso em: 04 jun. 2020 .

BRASIL. Lei $\mathbf{n}^{\circ} \mathbf{1 2 . 5 2 7}$, de 18 de novembro de 2014. Regula o acesso a informações previsto no inciso XXXIII do art. $5^{\circ}$, no inciso II do $\S 3^{\circ}$ do art. 37 e no $\S 2^{\circ}$ do art. 216 da Constituição Federal; altera a Lei ${ }^{\circ}$ 8.112, de 11 de dezembro de 1990; revoga a Lei $n^{\circ}$ 11.111, de 5 de maio de 2005, e dispositivos da Lei $\mathrm{n}^{\circ} 8.159$, de 8 de janeiro de 1991; e dá outras providências. Disponível em:http://www.planalto.gov.br/ccivil_03/_ato20112014/2011/lei/112527.htm. Acesso em: 04 jun. 2020.

BRASIL. Redes sociais, notícias falsas e privacidade de dados na internet. Pesquisa DataSenado, novembro/2019. Disponível em:https://www2.camara.leg.br/acamara/estruturaadm/ouvidoria/dados/pesquisa-nov-2019-relatorio-sem-tabelas. Acesso em: 05 jun. 2020.

BRISOLA, A.; BEZERRA, A. C. Desinformação e circulação de "fake news": distinções, diagnóstico e reação. Encontro Nacional de Pesquisa em Ciência da Informação, n. XIX ENANCIB, 2018.

CANOTILHO, J. J. G. Direito constitucional. 5. ed. Coimbra: Almedina, 1992.

CASTELLS, M. A sociedade em rede. São Paulo: Paz e Terra, 1999.

ESTADO DE ALAGOAS. Diário Oficial do estado de Alagoas - DOU. Disponível em: http://www.imprensaoficialal.com.br/wp-content/uploads/2020/06/DOEAL-10_06_2020COMPLETO.pdf. Acesso em 18 jun. 2020.

GIL, A. C. Como elaborar projetos de pesquisa. 5. ed. São Paulo: Atlas, 2008. 
GUERRA, M. D. G. G. V.; CARVALHO, K. A. G. Transparência pública e acesso à informação: a utopia virando realidade na UEPB. Comunicação \& Informação, v. 22, 2019. Disponível em:https://brapci.inf.br/index.php/res/v/123946. Acesso em: 05 jun. 2020.

HUIDU, A. (2020). The Social Responsibility of Researchers in Combating Fake News and Conspiracy Theories During a Pandemic. Postmodern Openings, 11(1Supl2), 39-48. Disponível em: http://apps-

webofknowledge.ez9.periodicos.capes.gov.br/full_record.do?product=WOS\&search_mode= GeneralSearch\&qid=2\&SID=8DJADNhRQIjwWPKjC4s\&page=2\&doc=20 Acesso em: 13 jun. 2020.

JARDIM, H. I. R; ZAIDAN, P. D. S. CONTROLE DE INFORMAÇÃO: uma análise sobre o papel da censura e da fake news na história brasileira. ERBD. Encontro Regional do Estudantes de Biblioteconomia, Documentação, Gestão e Ciência da Informação das Regiões Sudeste, Centro-oeste e Sul. Novembro de 2018. Belo Horizonte, Minas Gerais.

KEMP, S. Digital 2020: Brasil. In: Hootsuite e We Are Social. New York, 17 fev. 2020. Disponível em: https://datareportal.com/reports/digital-2020-brazil?rq=brazil. Acesso em: 16 jun. 2020.

LEMOS, V. Coronavírus: por que primeira pessoa infectada no Brasil pode nunca ser descoberta, BBC News Brasil, 2020. Disponível em:https://www.bbc.com/portuguese/brasil52334034. Acesso em: 14 jun. 2020.

LÉVY, P. Cibercultura. Tradução; Carlos Irineu da Costa. Editora 34, São Paulo, 1999.

MARCONI, M. D. A.; LAKATOS, E. M. Fundamentos de metodologia científica. 8. ed. São Paulo: Atlas, 2019.

MARQUES, A.; DELBARD, D. Comunicação Pública na Web: uma Reflexão Sobre a Aplicação dos Princípios da Web 2.0 no Fazer Comunicacional. In: Sociedade Brasileira de Estudos Interdisciplinares da Comunicação, 9., 2015, Rio de Janeiro. Anais do XXXVIII Congresso Brasileiro de Ciências da Comunicação. Rio de Janeiro: Intercom, 2015.

MARTINS, E. A.; GONÇALVES, K. C.; MIRANDA FILHO, R. Caracterizando a campanha presidencial brasileira em 2018 usando dados do Twitter. In: Brazilian Workshop on Social Network Analysis and Mining (BRASNAM), 8, 2019, Belém. Anais do VIII Brazilian Workshop on Social Network Analysis and Mining. Porto Alegre: Sociedade Brasileira de Computação, july 2019 . p. 131-142.

MELO, M. L. D. de; ROSA, M. N. B.; OLIVEIRA, B. M. J. F. de. Memória, Informação e Pós-verdade em tempos líquidos. ConCI: Conv. Ciênc. Inform., v. 3, n. 1, p. 25-41, jan./abr. 2020.

MOURA, A. R. P.; FURTADO, R. L.; BELLUZZO, R. C. B. Desinformação e competência em informação: discussões e possibilidades na Arquivologia. Ciência da Informação em Revista, Maceió, v. 6, n. 1, p. 37-57, jan./abr. 2019.

OLIVEIRA, T. M. D.; MARTINS, R. Q. R.; TOTH, J. P. Antivacina, fosfoetanolamina e Mineral Miracle Solution (MMS): mapeamento de fake sciences ligadas à saúde no Facebook. Reciis, v. 14, n. 1, 2020. 
OMS. Coronavirus disease (COVID-19) pandemic, 2020. Disponível em:https://www.who.int/emergencies/diseases/novel-coronavirus2019?gclid=CjwKCAjw8pH3BRAXEiwA1pvMsSS4LTIzHoaHUgI4E9FNQnDtpaVBn4rZbz tRBP-vhWOOHIYxXYq6ShoCnkkQAvD_BwE. Acesso em: 10 jul. 2020.

PINTO, P. A. et al. Marketing social e digital do ministério da saúde no instagram: estudo de caso sobre aleitamento materno. 2019. Disponível em: https://www.reciis.icict.fiocruz.br/index.php/reciis/article/view/1634. Acesso em: 14 jun. 2020.

REBS, R. R.; ZAGO, G. S. Redes sociais integradas e difusão de informações: compreendendo a circulação da informação em social games. Em Questão, v. 17, n. 2, p. 179-193, 2011.

RECUERO, R.; GRUZD, A. Cascatas de Fake News Políticas: um estudo de caso no Twitter. Galáxia, São Paulo, n. 41, mai/ago. 2019.

RODRIGUES, J. G. Publicidade, transparência e abertura na administração pública. Revista de Direito Administrativo, Rio de Janeiro, v. 266, p. 89-123, maio/ago. 2014.

RODRIGUEZ, A. R. Plano de presença digital: como posicionar o tribunal regional do trabalho da $10^{\mathrm{a}}$ região nas mídias sociais. 2016.

ROSA, T. C.; URBANETTO, R. P. A busca da transparência na gestão pública: lei de acesso à informação brasileira. Páginas A\&B, Arquivos e Bibliotecas (Portugal), n. 1, p. 138-145, 2014.

SANTOS, E. Pesquisa-Formação na Cibercultura. Teresina - PI. Editora EDIFPI, 2017.

SEVERO, M. L. Leia-me como uma história: mulheres e a construção de narrativas da felicidade no Instagram. 2017. Dissertação de Mestrado. Pontifícia Universidade Católica do Rio Grande do Sul. Disponível em:

http://repositorio.pucrs.br/dspace/bitstream/10923/10287/1/000483823-Texto\%2BCompleto0.pdf. Acesso em: 25 jun. 2020.

SILVA, D. M. D.; RIBEIRO, A. C. D.; SILVA FILHO, E. A. As redes sociais como ferramenta para acesso à informação na administração pública. Perspectivas em Políticas Públicas, v. 11, n. 21, p. 267-294, 2018.

SOUSA, A. M. D. O papel do bibliotecário como mediador da informação na era da pósverdade. Revista Brasileira de Biblioteconomia e Documentação, [s.1], v. 13, n. esp., p. 2390-2402, 2017.

STATISTA. Most popular social networks worldwide as of October 2019, ranked by number of active users. Disponível em: https://www.statista.com/statistics/272014/globalsocial-networks-ranked-by-number-of-users/. Acesso em: 13 jun. 2020.

TANIGUCHI, N. Covid-19: ponto a ponto sobre o novo coronavírus, Fiocruz Brasília, 2020. Disponível em: https://www.fiocruzbrasilia.fiocruz.br/covid-19-ponto-a-ponto-do-novocoronavirus/. Acesso em: 14 jun. 2020. 
TEIXEIRA, S. Novo Coronavírus (Covid-19): informações básicas, Rede Bibliosus, Ministério da Saúde, 2020. Disponível em:

https://bibliosus.saude.gov.br/index.php/artigos/14-noticias/244-novo-coronavirus-covid-19informacoes-basicas. Acesso em: 14 jun. 2020.

UNESCO. Jornalismo, Fake News \& Desinformação. Manual para Educação e Treinamento em Jornalismo. 2019. Disponível em:

https://unesdoc.unesco.org/ark:/48223/pf0000368647.nameddest=. Acesso em: 15 jun. 2019.

WE ARE SOCIAL. Digital in 2019. Disponível em: https://wearesocial.com/global-digitalreport-2019. Acesso em: 13 jun. 2020. 